\title{
Socio-political development of countries in information society. Countries of the EU
}

\author{
Nataliia Gavkalova ${ }^{1}$, Yuliia Lola $^{2, *}$, Svitlana Prokopovych $^{1}$, and Alina Zilinska ${ }^{1}$ \\ ${ }^{1}$ Simon Kuznets Kharkiv National University of Economics, Department of Public Administration, Kharkiv, 61166, Ukraine \\ ${ }^{2}$ Simon Kuznets Kharkiv National University of Economics, Department of Cybernetics, Kharkiv, 61166, Ukraine
}

\begin{abstract}
Many studies are devoted to the peculiarities of building the information society in the modern world and the problems of uneven development of information and communication technologies in developed and developing countries. This paper examines the influence of the information and communication technologies development on the social and political activities of modern society. The correlation and regression analysis has been used to identify the relationship between the Information and Communication Technology Development Index (ICT), the Human Development Index (HDI) and the Democracy Index (DI). The results demonstrate that there is a close link between the countries' sociopolitical attractiveness and the level of their information and communication development. However, it is not equal for different countries, which are grouped by the level of ICT, HDI and DI. Besides, the country's information and communication technologies level has a significant effect on the social and political development. The development of the information component immediately leads to improvement of the socio-political sphere in countries with high levels of HDI, DI and ICT. The EU countries belong to this cluster. Democracy development and ICT have the inverse relationship in the group of countries with average HDI, DI and ICT levels.
\end{abstract}

\section{Introduction}

The transition of the world society to the information society or knowledge society, the transformation of information technology into a generative force for the development of countries leads to the transformation of all spheres of human life. The ICT sector directly accounts for 5\% of Europe's GDP, with a market value of $€ 660$ billion. However, the level of influence of ICT on the overall growth of production is much higher $(20 \%$ directly from the ICT sector and $30 \%$ from investments in this field) [14]. Despite substantial investments in ICT in the public sector over the past decades, it has been hard to achieve consistent benefits. One reason for the difficulties is the gap between the expectations of key stakeholders (such as governments, businesses and citizens) and project outcomes [16].

ICT contributes to economic, social and political changes in society. This can be done through formation of unified databases and global platforms for the exchange of knowledge and best practices in all areas of life. At the same time, new opportunities and threats confront modern society. On the one hand, global information provides equal opportunities for all countries to join the global information platform, and on the other, it contributes to the gap between countries based on using advanced technologies, reinforcing economic and social inequality. In spite of attempting to implement e-government innovations to enhance efficiency in public organizations for several decades, e-government innovation has often not met the expectations of citizens, legislatures, or the organizations [17].

In the 20th century the most developed countries gradually entered the state of information society and it is expected that within a matter of a few decades the majority of the world's population will be living and working in a global information society [1].

Based on the analysis of social reality in the second half of the $20^{\text {th }}$ century, socio-historical reasons of "knowledge" and "information" concepts confusion have been defined. The relations between confusing these concepts and the formation of knowledge society concepts and information society ones are shown [2]. Across the European Union, indicators that measure information society emphasize many disparities and especially characteristics of this sector [3].

\section{Theoretical development and hypotheses formulation}

In recent years, progress in information and communication technology (ICT) has caused many structural changes such as reorganizing of economics, globalization, and trade extension, which leads to capital flows and enhancing information availability [21].

New character of cognitive processes is caused by the new informative means which have appeared together

\footnotetext{
* Corresponding author: yuliia.lola@hneu.net
} 
with the Internet, e-mail and system of mass communication. They connected the world in uniform space [4].

The Global Brain proposes a positive vision for a more sustainable society. The Global Brain can be defined as the distributed intelligence emerging from all human and technological agents as interacting via the Internet. It plays the role of a nervous system for the social superorganism [5].

The problems with current forms of electronic information systems (IS) implemented in human service organizations have been well documented and attention is now focused on how they might be redesigned for the future [18].

ICT carries the potential of opening economic opportunities, promoting social and political changes in society, providing access to knowledge, creating stimulus and a field for best practice sharing in all areas of life, the actual processes of informatization across the globe are quite asymmetrical [6]. Without internet access, which facilitates economic development and the enjoyment of a range of human rights, marginalized groups and developing States remain trapped in a disadvantaged situation, thereby perpetuating inequality both within and between States [7].

The statistical data points on the fact that it is necessary to increase the awareness of population regarding possibilities offered by using of ICT and eGovernment in Latvia [8]. The development of the information society and the introduction of new ICT in all spheres of society is determined by a priority of national public policy [9].

The level of information today is decisive in the socioeconomic development of the country [10].

There has been a proliferation of e-readiness assessment measures in recent years that each one has a certain objective. Based on definitions, objectives, dimensions, methods and approaches, in this paper, the measures are categorized and finally, a measure for ereadiness assessment is presented. The convergence measure for e-readiness assessment include some common indicators: infrastructure and access, access to and use of ICT by households and individuals, E-businesses, E-education, E-government, basic enabling indicators [9]. Contemporary enterprises can to improve the quality of information security solutions using structural analysis and design tools as CA All Fusion ERwin Data Modeler [10].

The impact of information society - as a factor of organizational change on performance of firms is increasingly approached and measured - by means of statistical indicators - in the specialty literature, developing in a fast pace. Across the European Union, indicators that measure information society emphasize many disparities and especially characteristics of this sector, aspects that will be detailed further, in this paper in order to justify the approach of this study [19].

The review of research induces us to formulate new hypotheses and enlarge the research sphere.

Hypothesis 1 . There is a direct correlation between the information and communication level and the socio- political development of societies in the countries of the world.

Hypothesis 2. This impact may be different in countries with different levels of information and communication development.

\section{Methods and data}

The methods of multivariate statistical analysis, such as descriptive statistics, the multiple regression and the cluster analysis were used to study the influence of information and communication technologies on sociopolitical level of development. These statistical methods were implemented with the StatSoft software package Statistica. This package has a wide range of functional data analysis algorithms and has wide graphical capabilities for data visualization.

To carry out the research, the global indices and variables of socio- political development were selected:

The Information and Communication Technologies Development Index (ICT) reflects the level of networked infrastructure and access to ICTs, the level of using of ICTs in the society and more efficient and effective ICT use [15]. This database was created by ICT Data and Statistics Division Telecommunication Development Bureau International Telecommunication Union.

The Human Development Index (HDI) is chosen to reflect the level of social development. The HDI is the geometric mean of normalized indices for each of the three dimensions: a long and healthy life, being knowledgeable and have a decent standard of living. The Human Development Ranking use to measure a country's development by the United Nations Development Programme [13].

The Democracy Index provides a snapshot of the state of democracy worldwide. The Democracy Index is based on five categories: electoral process and pluralism, civil liberties, the functioning of government, political participation and political culture [14]. Such data is collected by the Economist Intelligence Unit (EIU), the world leader in global business analysis.

107 countries of the world are the objects of research. The variables are the data for 2017 . The countries without sufficient data were excluded from the database.

\section{Results}

In order to study the influence of the country's information and communication development on the human development and level of democracy the following algorithm of the research is proposed:

Stage 1. Selection of the initial variables.

Stage 2. Research of the basic statistical characteristics of the selected variables (ICT, HDI, DI).

Stage 3. Verification of the first hypothesis on the basis of the correlation-regression analysis methods.

Stage 4. Verification of the second hypothesis on the basis of the correlation-regression and cluster analysis methods for the whole array of initial data and within the scope of separate groups of countries, which are similar a 
according to the level of country's information and communication development.

The inferential statistics reveal that relative advantage, compatibility, complexity, observability, and security are significant factors influencing internet-based ICT adoption [20].

For implementation of the first stage of the algorithm, the following variables were selected: The Information and Communication Technologies Development Index (ICT), The Human Development Index (HDI) and The Democracy Index (DI).

Descriptive statistics were used to process, systematize and provide a quantitative description of the empirical data by means of the main statistical indicators. The implementation of the second stage of the study presupposed the calculation of the following characteristics: Mean, Median, Mode, Frequency of Mode, Minimum, Maximum, Variance, Standard Deviation, Coefficient of Variation, Skewness, Kurtosis, as well as histogramming. The results of calculation are presented in Table 1.

Table 1. Descriptive statistics.

\begin{tabular}{|c|c|c|c|}
\hline \multirow{2}{*}{ Characteristics } & \multicolumn{3}{|c|}{ Variable } \\
\cline { 2 - 4 } ICT & HDI & DI \\
\hline Valid N & 107 & 107 & 107 \\
\hline Mean & 5.292 & 0.733 & 6.069 \\
\hline Median & 5.580 & 0.755 & 6.410 \\
\hline Mode & Multiple & Multiple & 5.11 \\
\hline Frequency & 2 & 2 & 3 \\
\hline Minimum & 1.270 & 0.404 & 1.500 \\
\hline Maximum & 8.980 & 0.953 & 9.870 \\
\hline Variance & 4.967 & 0.023 & 3.815 \\
\hline Std. Dev. & 2.229 & 0.150 & 1.953 \\
\hline Coef. Var. & 42.12 & 20.47 & 32.18 \\
\hline Skewness & -0.139 & -0.438 & -0.249 \\
\hline Kurtosis & -1.252 & -1.252 & -0.638 \\
\hline \multicolumn{4}{|c}{}
\end{tabular}

The results of the histogramming of distribution for each of the studied variables are presented in Fig. $1-3$.

According to the results of the analysis of the obtained statistical characteristics (see Table 1) and distribution histograms (Fig. 1-3), the following conclusions can be made:

- the ICT variable has a distribution rather close to normal. Its average value is close to the median. In 2017 this index had a significant spread (from 1,27 to 8,98), the value of this index in more than 45 countries differ from 6 to 9 . This means that a significant part of the countries in the considered group has a high level of development of information and communication technologies (ICT);

- the HDI variable also has a distribution close to normal. This variable has the least value of the coefficient of variation $(20,47 \%)$. The value of this index in a little more than $50 \%$ countries differ from 0,7 to 1 , that is nearly half of the researched countries of the world gets into the last three intervals. It has an insignificant left-side displacement (the skewness is equal to -0,438);

- the DI variable has a distribution close to normal. This is evidenced by the proximity of the mean, mode and median, as well as small values of the skewness and kurtosis.

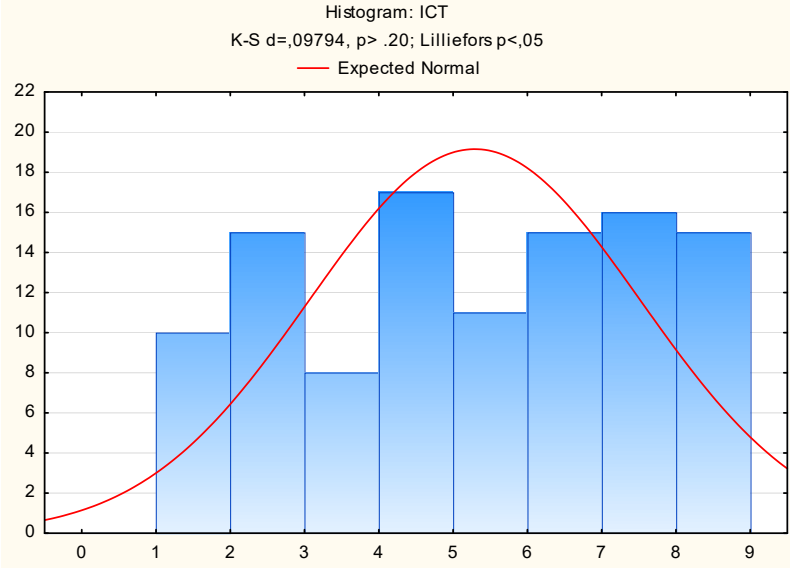

Fig. 1. ICT variable distribution histogram.

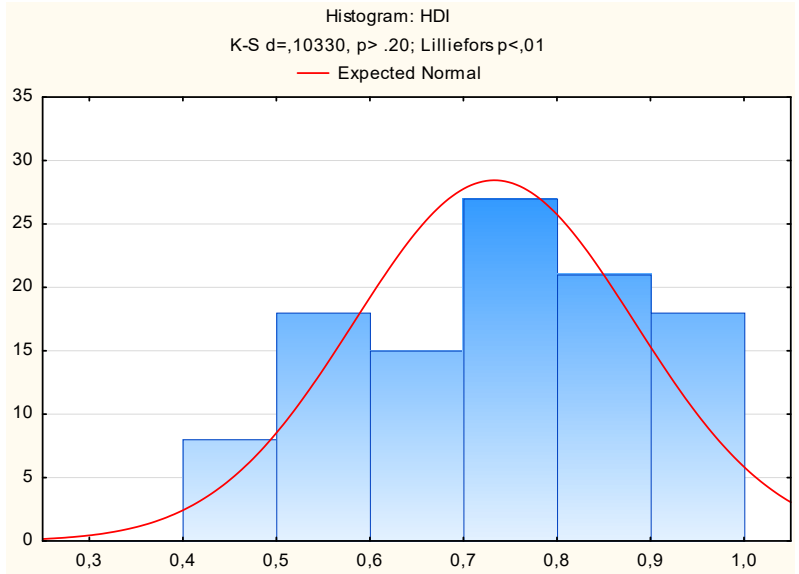

Fig. 2. HDI variable distribution histogram.

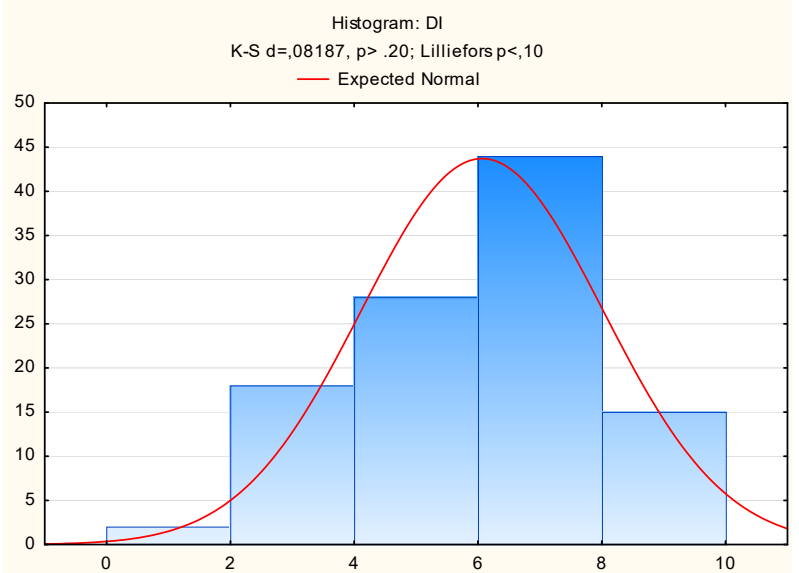

Fig. 3. DI variable distribution histogram.

Information and communication technologies (ICTs) are seen by many as a cost-effective and convenient means to promote openness and transparency and to reduce corruption [22].

ICT offer countries a new approach to creating transparency and promoting anti-corruption. Many nations with transparency laws have directly tied the implementation of these laws to the implementation of ICT-based initiatives, often through e-government.

Case studies and statistical analyses indicate that ICTs hold a great deal of potential for - and are already 
demonstrating benefits in - anti-corruption, particularly by enhancing the effectiveness of internal and managerial control over corrupt behaviors and by promoting government accountability and transparency.

The verification of the first hypothesis that the information development of the society contributes to the improvement of the country's social progress was carried out during the implementation of the third stage of the study. A pair correlation coefficient between the HDI, DI and ICT variables was calculated according to the data from all 107 countries. In 2017 it was equal to 0.9665 and 0.6887, which demonstrates the link between DI and ICT and, conversely, HDI and ICT.

The graphic representation of this connection is given in Fig. 4.

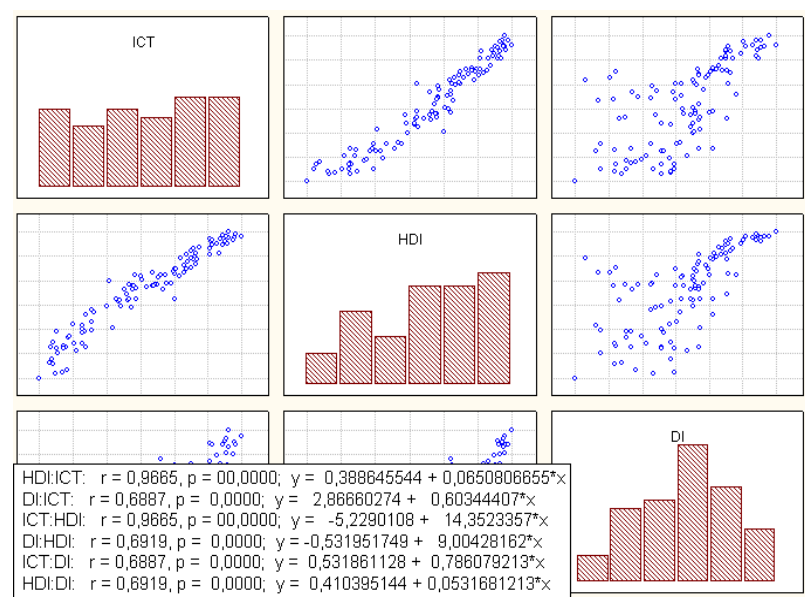

Fig. 4. Dispersion field (correlation field) between factors.

The dispersion field proves a linear relationship between DI, HDI and ICT. The closest connection is observed between ICT and the Index of Human Development $(r=0,9665)$. There is also a correlation between ICT and DI, but it is less close $(r=0,6887)$. Therefore, we can accept the hypothesis 1 that the greater the information development of the country is, the better socio-political sector is developed in this country. This enables putting forward the second hypothesis that this impact may be different in groups of countries identified in terms of their ICT levels.

To study the effect of ICT on HDI and DI, we construct a complex regression:

$$
\left\{\begin{array}{l}
\widehat{H D I}=a_{10}+a_{11} \cdot I C T, \\
\widehat{D I}=a_{20}+a_{21} \cdot I C T
\end{array}\right.
$$

where $a_{i j}$ - unknown parameters that are estimated with the help of ordinary least squares method (OLS).

Realisation of this model has been held with the help of STATISTICA package by gradual usage of OLS to each equation. The following results have been obtained:

$$
\left\{\begin{array}{l}
\widehat{H D I}=0.3886+0.065 \cdot I C T, \\
\widehat{D I}=2.8686+0.6047 \cdot I C T,
\end{array}\right.
$$

The data of regression equations are statistically significant on the whole by Fisher criterion $\left(F_{H D I}(1 ; 105)=1487.3, F_{D I}(1 ; 105)=95.45\right)$, and by certain parametres by Student's criterion $\left(t_{a_{10}}=40.14\right.$, $t_{a_{11}}=38.57, \quad t_{a_{20}}=8.08, \quad t_{a_{21}}=9.77$,). $\quad$ The coefficients of multiple correlation $\left(R_{H D I}=0.966\right.$, $\left.R_{D I}=0.69\right)$, determination coefficients $\left(R^{2}{ }_{H D I}=0.934\right.$, $\left.R^{2}{ }_{D I}=0.476\right)$ and adjusted determination coefficients $\left(R_{a d j_{H D I}}^{2}=0.933, R_{a d j_{D B}}^{2}=0.471\right)$ prove high quality of the model for HDI and medium quality for DI. There is no autocorrelation of errors (statistics of Durbin - Watson approximately equals to 1.9 , and cyclic coefficient of autocorrelation is rough 0 ) in the both models. So, we draw a conclusion that the given model can be used for analysis.

It can be noted that increase in ICT by one, will provoke increase in the HDI index approximately by 0.065 , and index DI - by 0.605 unities. This influence is direct and statistically significant.

Thus hypothesis 1 is proved.

Realization of the fourth stage presupposes verification of the second hypothesis that states: intensity of information development effect on economic development of countries is heterogeneous and can increase or decrease in various countries groups.

The following steps are proposed to verify this hypothesis:

Step 1. Countries disposal into homogeneous groups by values of indices HDI, DI and ICT based on cluster analysis methods.

Step 2. Construction of complex regression of the kind (1) for each of the clusters.

Step 3. Making conclusions.

At the first step with the help of cluster analysis methods we obtain homogeneous countries groups. The countries can be quite clearly allocated into two, three or five clusters (Fig. 5) on the basis of Ward's hierarchical method.

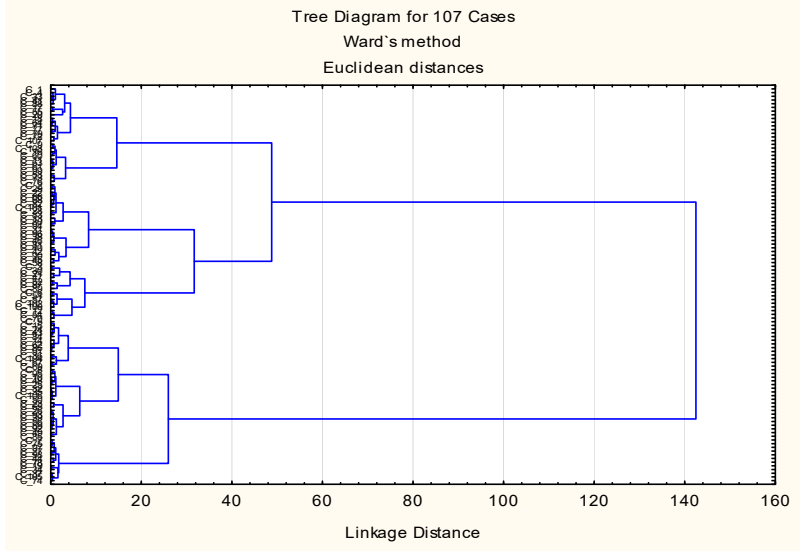

Fig. 5. Tree Diagram.

The division into two clusters is not informative. If we divide countries into five clusters, then the clusters with close average factor values will emerge. Therefore, it is rational to divide countries into three clusters, which corresponds to the logical distribution of countries with high, medium and low intensity of ICT development.

Based on the iterative method of clustering k-means, the following cluster results have been obtained. The first cluster includes 36 countries with the highest level of ICT 
(cluster contains 36 cases). These countries are listed in Table 2.

Table 2. Members of Cluster Number 1 and Distances from Respective Cluster Center

\begin{tabular}{|c|c|c|c|}
\hline Country & Distance & Country & Distance \\
\hline Argentina & 0.840 & Finland & 0.557 \\
\hline Australia & 0.658 & France & 0.342 \\
\hline Austria & 0.264 & Germany & 0.496 \\
\hline Belgium & 0.181 & Greece & 0.535 \\
\hline Bulgaria & 0.783 & Hungary & 0.947 \\
\hline Canada & 0.620 & Iceland & 1.133 \\
\hline Costa Rica & 0.748 & Israel & 0.192 \\
\hline Croatia & 0.881 & Italy & 0.395 \\
\hline Cyprus & 0.284 & Japan & 0.428 \\
\hline Czech Republic & 0.417 & Latvia & 0.547 \\
\hline Denmark & 0.874 & Lithuania & 0.492 \\
\hline Estonia & 0.296 & Mauritius & 1.065 \\
\hline Netherlands & 0.648 & Slovenia & 0.387 \\
\hline New Zealand & 0.769 & Spain & 0.042 \\
\hline Norway & 1.122 & Sweden & 0.857 \\
\hline Poland & 0.943 & Switzerland & 0.807 \\
\hline Portugal & 0.366 & United Kingdom & 0.599 \\
\hline
\end{tabular}

Almost all EU countries (except Romania) are in this cluster. These countries have a high level of the Democracy Index (DI), information and communication technologies development (ICTs) and the Human Development Index.

The second cluster includes 41 countries with an average level of ICT (cluster contains 41 cases) and is presented in Table 3.

Table 3. Members of Cluster Number 2 and Distances from Respective Cluster Center.

\begin{tabular}{|c|c|c|c|}
\hline Country & Distance & Country & Distance \\
\hline Albania & 0.27 & El Salvador & 0.99 \\
\hline Algeria & 1.19 & Georgia & 0.37 \\
\hline Armenia & 0.87 & Ghana & 0.97 \\
\hline Bolivia & 0.56 & India & 1.62 \\
\hline Botswana & 1.37 & Indonesia & 0.73 \\
\hline Brazil & 0.91 & Iran & 1.79 \\
\hline China & 1.42 & Jordan & 1.05 \\
\hline Colombia & 0.65 & Kazakhstan & 1.74 \\
\hline Dominican Rep. & 0.78 & Kyrgyzstan & 0.58 \\
\hline Ecuador & 0.37 & Lebanon & 0.76 \\
\hline Egypt & 1.31 & Malaysia & 0.86 \\
\hline Mexico & 0.51 & Saudi Arabia & 2.24 \\
\hline Moldova & 0.72 & Serbia & 0.92 \\
\hline Mongolia & 0.58 & South Africa & 1.00 \\
\hline Montenegro & 0.68 & Sri Lanka & 0.96 \\
\hline Morocco & 0.49 & Thailand & 0.57 \\
\hline Panama & 0.91 & Tunisia & 0.52 \\
\hline Paraguay & 0.77 & Turkey & 0.60 \\
\hline Peru & 0.60 & Ukraine & 0.22 \\
\hline Philippines & 0.76 & Russian Federation & \multirow{2}{*}{1.72} \\
\hline Romania & 0.87 & \multicolumn{3}{|c}{} \\
\cline { 1 - 2 } & \multicolumn{3}{|c}{}
\end{tabular}

Countries in the cluster 2 are characterized by the average level of ICT and socio-political development. Ukraine is referred to this group.

To further develop the understanding of the conditions of unrealized benefits of e-government innovation, we propose a conceptual framework of a knowledge vacuum, which is an organizational condition in which excessive exploration and organizational inertia interact to create a vicious cycle of low performance. We first review the history of e-government and factors that affect the success and failure of e-government innovation.

The third cluster includes 30 countries with the low level of ICT (cluster contains 30 cases). This cluster is presented in Table 4.

Table 4. Members of Cluster Number 3 and Distances from Respective Cluster Center.

\begin{tabular}{|l|c|l|c|}
\hline \multicolumn{1}{|c|}{ Country } & Distance & Country & Distance \\
\hline Afghanistan & 1.089 & Ethiopia & 0.707 \\
\hline Angola & 0.516 & Guatemala & 1.016 \\
\hline Bangladesh & 0.612 & Guinea & 0.803 \\
\hline Benin & 0.760 & Honduras & 0.925 \\
\hline Burkina Faso & 0.368 & Kenya & 0.513 \\
\hline Cambodia & 1.166 & Lao PDR & 1.197 \\
\hline Cameroon & 0.445 & Lesotho & 1.355 \\
\hline Chad & 1.789 & Madagascar & 0.595 \\
\hline Malawi & 0.748 & Pakistan & 0.072 \\
\hline Mali & 0.744 & Rwanda & 0.699 \\
\hline Mauritania & 0.334 & Senegal & 1.032 \\
\hline Mozambique & 0.221 & Tanzania & 0.717 \\
\hline Myanmar & 0.468 & Uganda & 0.429 \\
\hline Nepal & 0.537 & Zimbabwe & 0.764 \\
\hline
\end{tabular}

Countries of the latter cluster are characterized by the lowest level of ICT, HDI and DI.

This is also confirmed by the calculation of the pair correlation coefficients between the variables for each cluster separately. The results of calculations are presented in the Table 5.

Table 5. Matrices of the pair correlation coefficients for each cluster.

\begin{tabular}{|c|c|c|c|}
\hline \multicolumn{4}{|c|}{ Cluster 1 } \\
\hline Variable & ICT & HDI & DI \\
\hline ICT & 1 & 0.898 & 0.697 \\
\hline HDI & 0.898 & 1 & 0.743 \\
\hline DI & 0.697 & 0.743 & 1 \\
\hline \multicolumn{4}{|c|}{ Cluster 2 } \\
\hline Variable & ICT & HDI & DI \\
\hline ICT & 1 & 0.740 & -0.442 \\
\hline HDI & 0.740 & 1 & -0.364 \\
\hline DI & -0.442 & -0.364 & 1 \\
\hline \multicolumn{4}{|c|}{ Cluster 3 } \\
\hline Variable & ICT & HDI & DI \\
\hline ICT & 1 & 0.750 & 0.244 \\
\hline HDI & 0.750 & 1 & 0.186 \\
\hline DI & 0.244 & 0.186 & 1 \\
\hline
\end{tabular}

We analyze the means of the obtained coefficients in more detail.

Firstly, cluster number 1 is formed from countries with the highest values of indices ICT, HDI and DI. The second cluster is constituted by countries with a middle level of ICT, GC and DI. The third cluster comprises countries with the lowest level of ICT, HDI and DI. 
At the second step of the proposed algorithm we build complex regression of the kind (1) and get the following results.

For cluster 1 (with a high level of development):

$$
\left\{\begin{array}{c}
\widehat{H D I}=0.473+0.054 \cdot I C T, \\
\widehat{D I}=1.625+0.836 \cdot I C T,
\end{array}\right.
$$

The data of the regression equation are statistically significant on the whole by Fisher criterion $\left(F_{H D I}(1 ; 34)=142,18, \quad F_{D I}(1 ; 34)=32,08\right)$, and by certain parametres by Student criterion $\left(t_{a_{10}}=13.51\right.$, $t_{a_{11}}=11.92, t_{a_{21}}=5.66$,). But parameter $a_{20}$ is statisticaly unsignificant $\left(t_{a_{20}}=1.42 ; P\right.$-value $\left.=0.16\right)$. Coefficients of multiple correlation $\left(R_{H D I}=0.898\right.$, $\left.R_{D I}=0.697\right)$, determination coefficients $\left(R_{H D I}^{2}=\right.$ $\left.0.807, R_{D I}^{2}=0.485\right)$ and adjusted determination coefficients $\left(R_{a d j_{H D I}}^{2}=0.801, R_{a d j_{D I}}^{2}=0.47\right)$ indicate not quite high quality of the model.

For cluster 2 (with a middle level of development):

$$
\left\{\begin{array}{c}
\widehat{H D I}=0.526+0.041 \cdot I C T, \\
\widehat{D I}=9.144-0.683 \cdot I C T,
\end{array}\right.
$$

The data of regression equation are statistically significant on the whole by Fisher criterion $\left(F_{H D I}(1 ; 39)=47.158, \quad F_{D I}(1 ; 39)=9.49\right), \quad$ and by certain parameters by Student criterion $\left(t_{a_{10}}=16.29\right.$, $\left.t_{a_{11}}=6.87, t_{a_{20}}=7.69,\left|t_{a_{21}}\right|=3.08\right)$. Coefficients of multiple correlation $\left(R_{H D I}=0.74, \quad R_{D I}=0.442\right)$, determination coefficients $\left(R_{H D I}^{2}=0.547, R_{D I}^{2}=0.196\right)$ and adjusted determination coefficients $\left(R_{a d j_{H D I}}^{2}=0.536, R_{a d j_{D I}}^{2}=0.175\right)$ indicate the model quality which is a little lower than for the model (3).

It should be noted that this cluster is also characterized by inverse relationship between HDI and DI. The even correlation coefficient between these indicators is equal to -0.364 (see Table 5).

For cluster 3 (with a low level of development):

$$
\left\{\begin{array}{c}
\widehat{H D I}=0.327+0.085 \cdot I C T, \\
\widehat{D I}=3.079+0.541 \cdot I C T,
\end{array}\right.
$$

By Fisher criterion only the equation for HDI $\left(F_{H D I}(1 ; 28)=36.09\right)$ is statistically significant on the whole, while for DI $F_{D I}(1 ; 28)=2.95$, and significance $F=0.0955$. By Student criterion the significant parametres are $a_{10}, a_{11}$ and $a_{20}\left(t_{a_{10}}=9.3, t_{a_{11}}=6.0\right.$, $\left.t_{a_{20}}=3.07\right)$, while the parametre $a_{21}$ is statistically insignificant $\quad\left(t_{a_{21}}=1.33, P-\right.$ value $\left.=0.19\right)$. Coefficients of multiple correlation $\left(R_{H D I}=0.75, R_{D I}=\right.$ $0.244)$, determination coefficients $\left(R_{H D I}^{2}=0.563\right.$, $\left.R_{D I}^{2}=0.06\right)$ and adjusted determination coefficients $\left(R_{a d j_{H D I}}^{2}=0.547, R_{a d j_{D I}}^{2}=0.026\right)$ differ significantly for these two equations that indicates quite high quality of HDI model and low model quality for DI.

Analyses values of regression coefficients in models (2) - (5) that are given in Table 6 to research the changes in the influence of ICT on HDI and DI in each cluster.
Table 6. Regression coefficients.

\begin{tabular}{|c|c|c|c|c|c|}
\hline Model & Coefficients & Total & Cluster 1 & Cluster 2 & Cluster 3 \\
\hline \multirow{2}{*}{ HDI } & $a_{10}$ & 0.3886 & 0.473 & 0.526 & 0.327 \\
\cline { 2 - 6 } & $a_{11}$ & 0.065 & 0.054 & 0.041 & 0.085 \\
\hline \multirow{2}{*}{ DI } & $a_{20}$ & 2.8686 & 1.625 & 9.144 & 3.079 \\
\cline { 2 - 6 } & $a_{21}$ & 0.6047 & 0.836 & -0.683 & 0.541 \\
\hline
\end{tabular}

As we can see from Table 6 a higher value of Intercept $\left(a_{10}\right)$ is characteristic for cluster 1 by the HDI index in comparison with the whole set of data, but the lowest value of the slope angle $\left(a_{11}\right)$ of the regression line. Cluster 2 is characterized by the highest value of Intercept $\left(a_{10}\right)$, and a little lower of the value of $a_{11}$ in comparison with other clusters and the whole option. Cluster 3 is characterized by the lowest value of Intercept $\left(a_{10}\right)$, but the highest value of the slope angle $\left(a_{11}\right)$ of the regression line. It means that the speed of HDI reaction to ICT increase will be the lowest for cluster 2 , and the highest for cluster 3 .

The situation is similar to DI index. The change speed of DI index under the influence of ICT is the lowest for countries with a low level of economic development and the highest for countries from cluster 1 . But «the starting conditions», that is the coefficient value $a_{20}$, are much higher for cluster 2 .

Thus, based on the aforementioned, hypothesis 2 for all groups of the countries is rejected.

Further researches are aimed at studying the stability of the identified dependencies over time.

\section{Conclusion}

The study allows us to draw such conclusions:

1) the result of the correlation-regression analysis indicates that there is a strong correlation between ICT and HDI levels, and a moderate correlation between ICT and human development. Therefore, the first hypothesis was confirmed;

2) in countries with high levels of HDI, DI, and ICT, the link between these indicators of societal development is higher than average. Accordingly, the development of the information component immediately leads to the improvement of the socio-political sphere. The EU countries belong to this cluster. At the same time, EU candidate countries (Albania, Northern Macedonia, Serbia, Turkey, Montenegro) belong to the second cluster, in which the impact of ICT on other spheres of life is different, which creates additional difficulties for the formation of united informational, social, economic and political space;

3) an unexpected result was obtained during the study of the group of countries with average HDI, DI and ICT levels. The distribution field and correlation-regression analysis indicate the inverse relationship between DI and ICT. This is because the spread of Internet technologies and social networks provides a powerful tool for manipulation of public opinion, which is especially relevant when applying political technologies. Studies have shown that this does not always lead to improvements in electoral process, civil liberties, government functioning, political participation, and 
political culture. These contrasts can stimulate debate about government policy priorities.

The suggested model can be also detailed and extended according to the dynamic of Information and Communication Development Index, Human Development Index and Democracy Index over time. Moreover, considerable disparities are also related to the different economic past of the countries (developed countries, developing countries, politically unstable countries) and thus the model suggested for this paper can be completed with qualitative variables.

\section{References}

1. N. Gavkalova, I. Kolupaev et al, State. watered. 17, 216-225 (2018)

2. A. Karpov, The problem of separating the notions of "knowledge" and "information" in the knowledge society and its education, in 7th International Conference on Intercultural Education "EDUHEM", Almeria, Spain 15-17 June 2016

3. L. Cîmpian, E. Lazar, M. Rozalia Gabor, Order econom. and Fin. 15, 1578-1586 (2014)

4. N. Pogukaeva, Procedia - Social and Behavioral Sciences 166, 456-459 (2015)

5. F. Heiligen, M. Lenartovich, Technol. forecast. and social amend. 114, 1-6 (2017)

6. B. Schlichter, L. Danilchenko, Inform. 31, 170-184 (2014)

7. D. Joyce, Internet Freedom and Human Rights. European Journal of International Law 26, 493-514 (2015). doi:10.1093/ejil/chv021

8. P. Hanafizade, M. Hanafizade, Upr. inf. 29, 189-195 (2009)

9. V. Babenko, V. Petuhova, A. Perepelitsia, Forming of informatization strategic prospects for Ukraine in conditions of world economy globalization. Scientific Bulletin of Polissia 1(2(10)), 24-34 (2017)

10. V. Babenko, V. Perevozova, O. Mandych, T. Kvyatko, O. Maliy, I. Mykolenko, World informatization in conditions of international globalization: Factors of influence. Global Journal of Environmental Science and Management 5 (Special issue), 172-179 (2019)

11. L. Chagovets, S. Prokopovych, V. Chahovets, Science and technology October, 265-270 (2018)

12. Homepage of the Democracy Index (2017), http://www.eiu.com/home.aspx\#offer-ss-data. Accessed 21 Mar 2017

13. Homepage of the ICT Development Index (2017), https://www.itu.int/net4/ITU-

D/idi/2017/index.html\#idi2017rank-tab. Accessed 21 Mar 2017

14. Homepage of the Human Development Index (2017), http://hdr.undp.org/en/content/human-developmentindex-hdi. Accessed 21 Mar 2017

15. Europe Union, Digital agenda for Europe (Publications Office of the European Union, Luxembourg, 2014)
16. J. Rose, L. Skiftenes Flak, Stakeholder theory for the E-government context: Framing a value-oriented normative core. Government Information Quarterly 35(3), 362-374 doi:10.1016/j.giq.2018.06.005

17. T. Choi, S. Meyers Chandler, Knowledge vacuum: An organizational learning dynamic of how egovernment innovations fail. Government Information Quarterly 37(1) (2020). doi:10.1016/j.giq.2019.101416

18. P. Gillingham, Electronic information system in human service organizations: Using theory to inform future design. International Social Work, 60 (1), 100$110(2017)$

19. L. Cîmpiana, E. Lazarb, M. Rozalia Gabor, Econometric Modeling of Influence on Turnover Concerning Indicators of Information Society Across the European Union. Procedia Economics and Finance, 15, 1578-1586 (2014). doi:10.1016/S22125671(14)00628-5

20. K.S. Tan, S.C. Chong, B. Lin, U.C. Eze, Internetbased ICT adoption: Evidence from Malaysian SMEs. Industrial Management and Data Systems 109(2), 224-244 doi:10.1108/02635570910930118

(2009).

21. M. Farhadi, R. Ismail, M. Fooladi. Information and Communication Technology Use and Economic Growth 7(11), doi:10.1371/journal.pone.0048903

(2012).

2. J.C. Bertot, P.T. Jaeger, J.M. Grimes, Using ICTs to create a culture of transparency: E-government and social media as openness and anti-corruption tools for societies. Government Information Quarterly 27(3), 264-271 (2010). doi:10.1016/j.giq.2010. 03.001 